\title{
LAS RELACIONES ENTRE ESTADO E IGLESIA EN EL PENSAMIENTO AFRANCESADO EN ESPAÑA*
}

\author{
RELATIONSHIPS BETWEEN THE STATE AND THE CLERGY IN \\ AFRANCESADOS' THOUGH IN SPAIN
}

\author{
RELAÇÕES ENTRE O ESTADO E A IGREJA EM PENSAR AFRANCESADO \\ NA ESPANHA
}

\author{
JOSÉ ANTONIO LORENZO CUESTA** \\ Universidad Nacional de Educación a Distancia \\ MARÍA ELENA NEVARES MIGUEL*** \\ Universidad Nacional de Educación a Distancia \\ https://doi.org/10.46553/EHE.22.2.2020.p124-140
}

\begin{abstract}
Resumen
Este artículo pretende demostrar que el corpus ideológico del clero afrancesado se fundamentaba en la concepción de un sistema constitucional caracterizado por la asunción de un concepto moderado de la soberanía (de cartas otorgadas) y de oposición al concepto de la soberanía popular. La ideología política representada por el sector del clero afrancesado, la que más adelante se llamaría doctrinaria, explicaría que no solo el espíritu nacional alimentara el odio del partido liberal español contra los invasores, sino que fuera determinante en el nacimiento de una causa política.
\end{abstract}

\section{Palabras clave}

afrancesado - doctrinario - clero - Estado - traición.

\begin{abstract}
This article tries to demonstrate that the ideological corpus of the afrancesado clergy was based on the conception of a constitutional system characterized by the assumption of a moderate concept of sovereignty (of granted letters) and of opposition to the concept of popular sovereignty. The political ideology represented by the sector of the afrancesado clergy, which would later be called doctrinaire, would explain that not only the national spirit fueled the hatred of the Spanish liberal party against the invaders, but also that it was determining in the birth of a political cause.
\end{abstract}

\section{Keywords}

afrancesado - doctrinaire - clergy - State - treason.

\section{Resumo}

Este artigo tenta demonstrar que o corpus ideológico do clero frenchificado se baseou na concepção de um sistema constitucional caracterizado pela suposição de um conceito moderado de soberania (de cartas concedidas) e de oposição ao conceito de soberania popular. A ideologia política representada pelo setor do clero frenchificado, que mais tarde seria chamado de doutrina, explicaria que não apenas o espírito nacional alimentava o ódio do partido liberal espanhol contra os invasores, mas que estava determinando no nascimento de uma causa política.

\section{Palavras-chave}

afrancesado - doutrinário - clero - Estado - traição. 


\section{Antecedentes históricos}

La tendencia, surgida en Occidente, hacia la secularización de la sociedad y limitación de lo religioso al ámbito de la privacidad ha constituido un proceso histórico que comenzó en el Renacimiento y se consolidó en la Ilustración. ${ }^{1}$ En ese momento de la historia, el ser humano fue concebido como un ente libre del poder religioso e iluminado por la luz de la razón. ${ }^{2}$ Las revoluciones burguesas derribaron la rígida sociedad estamental característica del Antiguo Régimen que había legitimado la religión. El liberalismo burgués supo imponer su propio corpus ideológico basado en la idea de la propiedad y el triunfo social logrado mediante el esfuerzo y la valía personal, sin desdeñar el sentimiento religioso de gran parte de la población. ${ }^{3}$ De este modo, la burguesía pretendía lograr la estabilidad política necesaria para constituirse en la élite dirigente del nuevo orden social nacido sobre las ruinas del Antiguo Régimen. La expansión del ejército de Napoleón llevó a las tierras conquistadas una nueva concepción de las relaciones que debían mantener el Estado y la Iglesia. Esta idea se basaba en la primacía estatal y en la obligación del Estado de evitar cualquier coerción de la religión sobre el nuevo ideario expandido por las tropas francesas y por la multitud de publicaciones que, a pesar de las dificultades de su difusión, influyeron en la intelectualidad ilustrada hispana.

Las relaciones entre el Estado y la Iglesia en la España del siglo XVIII fueron mediatizadas por el regalismo borbónico y los Concordatos de 1717, 1737 y 1753. Durante el reinado de Carlos III, las relaciones entre Estado e Iglesia no estuvieron exentas de polémicas, aunque puede decirse que se mantuvieron dentro de un cierto espacio de respeto mutuo y estabilidad institucional. ${ }^{4} \mathrm{El}$ reinado de Carlos IV se vio influenciado por el estallido de la Revolución francesa. A pesar de todo, las tradicionales relaciones entre trono y altar no se vieron sustancialmente afectadas por los acontecimientos revolucionarios en Francia. La "cruzada" contra la Convención francesa asentó, aún más, las buenas relaciones entre el Estado y la Iglesia. ${ }^{5}$ Esta idílica situación cambió radicalmente como consecuencia de la invasión del país por las tropas napoleónicas y la consecuente Guerra de la Independencia, transcurrida en España entre los años 1808 y 1814. La Gaceta de Madrid, de 10 de mayo de 1808, publicó la renuncia a la corona del rey, príncipe de Asturias, y de SS.AA. los infantes D. Carlos y D. Antonio. El rey, en su renuncia, ponía de manifiesto la extraordinaria situación que provocó su decisión.

Además, se comunicaba a los españoles que el pacto firmado con Napoleón consideraba a "nuestra sagrada religión", como la única observable en el reino. De igual

\footnotetext{
* Fecha de recepción: 22/04/2020. Fecha de aceptación: 21/07/2020.

** Doctor en Historia, Universidad de Valladolid, Universidad Nacional de Educación a Distancia (UNED), Centro Asociado en Palencia, Calle la Puebla, 6, 34002, Palencia, España, ORCID 0000-0003-1100-0498, joslorenzocuesta@hotmail.com

*** Licenciada en Ciencias Políticas, UNED, Centro Asociado en Palencia, Calle la Puebla, 6, 34002, Palencia, España, ORCID 0000-0003-2263-0145, elenanevares@ hotmail.com.

1 JOVER ZAMORA, 1976.

${ }^{2}$ Esta nueva concepción de la libertad religiosa se acentuó con el liberalismo y el positivismo.

${ }^{3}$ VELASCO MOLPECERES, 2016.

${ }^{4}$ Hitos importantes de esta etapa fueron la creación del Tribunal de la Rota, que recortaba las jurisdicciones delegadas de la Nunciatura, o la creación de la Agencia General de Preces, creada en Madrid para regular las solicitudes y concesiones de las dispensas tramitadas en Roma.

${ }^{5}$ MORALES MOYA, 1993, p. 17.
} 
manera, SS.AA., en su escrito de renuncia, manifestaban el compromiso del emperador de Francia de mantener la unidad religiosa. ${ }^{6}$

En el Decreto de convocatoria de la Asamblea de Bayona, dado el 19 de mayo de 1808, Napoleón determinó el número de miembros pertenecientes al clero. Desde el principio trató de ganarse el apoyo de este estamento, y así, de los ciento cincuenta vocales, un tercio pertenecía al brazo eclesiástico: dos arzobispos, seis obispos, dieciséis canónigos, veinte curas párrocos y seis generales de órdenes religiosas. ${ }^{7}$ De ellos, treinta y cinco presentaron sus excusas para no asistir a la convocatoria. Algunos de los ausentes fueron considerados como patriotas, como el Obispo de Orense, Pedro de Quevedo y Quintano. Su fama de persona íntegra le convertiría en candidato de la Junta Central para presidir la Regencia. Él mismo había considerado no válidas las renuncias de Bayona. Dos años después, el día 24 de septiembre de 1810, presidió la sesión inaugural de las Cortes de Cádiz, en la Isla de León. ${ }^{8}$ La primera reunión de la Asamblea de Bayona se celebró en el Palacio del Obispado Viejo, el día 15 de junio de 1808. Asistieron a la Asamblea un total de sesenta y cinco diputados. ${ }^{9}$ Napoleón nombró a su hermano José como rey de España con el respaldo jurídico del Estatuto de Bayona. El día 7 de julio de 1808, el rey José I acudió a la Asamblea para prestar y recibir el juramento debido. Los objetos relacionados con el poder eclesiástico, tales como el báculo, y otros objetos litúrgicos se pusieron a disposición del nuevo rey. Al inicio de su reinado, José Bonaparte envió una circular a los arzobispos y obispos en la que les solicitaba que en las iglesias del reino se rezara por la paz y se cantaran los triunfos logrados por el emperador de Francia, a la vez que pedía que se llevara a cabo la celebración de la onomástica de San Napoleón. ${ }^{10}$ Con la pretensión de ganarse el favor del pueblo, se reconocía al catolicismo como la religión tradicional de España. La propia Carta Otorgada de Bayona comenzaba "En el nombre de Dios todo poderoso D. José Napoleón, por la gracia de Dios rey de las Españas y de las Indias." 11

Sin embargo, lejos de lograr su objetivo, el emperador consiguió que el estamento clerical reafirmase su tradicional alianza con el trono español y se enfrentase sobre el terreno bélico al invasor francés con varios de sus miembros como destacados guerrilleros. ${ }^{12}$ Las reformas introducidas por José I en el terreno religioso pretendían cambiar de forma radical las provechosas relaciones previas entre la Iglesia y el Estado. El hermano de Napoleón pretendía abolir la Inquisición y, asimismo, reducir el número de religiosos, desamortizar los bienes pertenecientes al clero regular, llevar a cabo la transformación de edificios religiosos en civiles, suprimir la jurisdicción de los prelados en casos civiles y criminales y procurar el nombramiento de obispos adictos al régimen josefino para poder sustituir a aquellos otros más contestatarios con el rey francés. El sentimiento religioso del pueblo español formaba parte de su herencia cultural y el estamento clerical había desempeñado desde la Edad Media un papel protagonista no solo en el ámbito propio de su actividad, sino muy especialmente en el espacio político. No en vano, en la Cortes de Cádiz de 1812, un tercio del total de los diputados presentes pertenecían al clero, lo que influyó de forma decisiva en su posición conservadora respecto al papel que la Iglesia habría de desempeñar tras la desaparición del Antiguo Régimen. Tanto es así, que la Constitución de 1812, en su artículo 12, reconocía a la

\footnotetext{
${ }^{6}$ PÉREZ SÁENZ DE URTURI, 1985, pp. 55-62.

${ }^{7}$ SANZ CID, 1922, p. 82.

${ }^{8}$ MORENO ALONSO, 2014, p. 120.

${ }^{9}$ FERNÁNDEZ SARASOLA, 2007, p. 271.

${ }^{10}$ Gaceta de Madrid, 25 de enero de 1809.

${ }^{11}$ Constitución de Bayona de 1808, p. 1.

12 BARBASTRO GIL, 2008, pp. 267-275.
} 
religión católica como "única, verdadera, perpetua y verdaderamente enraizada en la tradición española."13

\section{La Iglesia y la Monarquía española en el inicio de la contemporaneidad}

Durante el reinado de Carlos IV, merced al buen hacer de Godoy, las relaciones entre la Monarquía española y la Santa Sede podrían calificarse de satisfactorias para ambas partes. Durante los pontificados de Pío VI y Pío VII, el príncipe de la paz fue un aliado fiel en una etapa de no pocas dificultades para la Iglesia romana, por lo que los pontífices mostraron su agradecimiento al valido español por este incondicional apoyo. ${ }^{14}$

A la muerte de Pío VI, Roma se hallaba en poder de Francia. En Venecia, treinta y cinco cardenales desterrados se reunieron con la intención de celebrar un cónclave en el convento de San Jorge el Mayor y elegir, como Papa, a Gregorio Bernabé, descendiente de los condes de Chiaramonti, cardenal obispo de Imola, que adoptó el nombre de Pío VII. Esta elección suponía un triunfo para la religión católica y un fracaso para Francia cuando se confiaba en que, después de Pío VI, ningún otro Papa ocuparía la silla de san Pedro. Napoleón pensaba subyugar al pontífice, de igual modo que había sometido a los reyes a su supremacía imperial. El día 21 de marzo de 1800, se llevó a cabo la coronación de Pío VII. El nuevo pontífice recibió las felicitaciones de los embajadores de Cerdeña, de Nápoles y de España. Para Pío VII, el restablecimiento del poder de la religión católica constituía un aval para la restauración del orden estatal. En 1809, tras la invasión de los Estados Pontificios por las tropas napoleónicas, el Papa Pío VII decidió la excomunión de Napoleón, lo que provocó la ruptura de las relaciones diplomáticas con la Santa Sede. Ante tal circunstancia, José I ordenó que todos los miembros de la Nunciatura y del Tribunal de la Rota salieran de España. ${ }^{15}$

Mientras la Iglesia de Roma profesaba muestras de afecto hacia Godoy, la jerarquía eclesiástica española sentía un verdadero desprecio hacia la figura del duque de Alcudia. Si bien Godoy fue un aliado del Papado, en aquellos asuntos en los que Roma requería de su ayuda, su interés se basaba en la esperanza de que el Papa, en agradecimiento, le correspondiera con un firme apoyo a las reformas que Godoy pretendía efectuar en la Iglesia española, dirigidas especialmente a conseguir que el clero español sirviera a la Monarquía. ${ }^{16}$

Godoy, acérrimo regalista, no dudó en recordar que en España, por encima del poder espiritual se hallaba el poder de la Monarquía española. ${ }^{17}$ La sumisión de la Iglesia

\footnotetext{
${ }^{13}$ GORÁFANO SÁNCHEZ; PÁRAMO ARGÜELLES, 1987, pp. 28-32.

${ }^{14}$ Pío VII concedía al príncipe de la paz, como era conocido Godoy, el derecho a disponer de un oratorio privado. El aprecio del Papa era tal, que, con motivo del nacimiento de la hija de Godoy, Pío VII le hacía llegar su felicitación mediante Filippo Casoni, nuncio en Madrid entre 1795 a 1803 y secretario de Estado de Su Santidad entre los años 1806-1807. DÍAZ DE CERIO RUIZ, 1988, p. 219.

${ }^{15}$ MORENO ALONSO, op. cit., p. 179.

${ }^{16}$ El Papa había solicitado la intermediación de Godoy en asuntos tan sensibles para su propia existencia como la amenaza napoleónica sobre los Estados Pontificios en 1800.

${ }^{17}$ El 5 de septiembre de 1794, Godoy enviaba una carta al arzobispo de Valencia, Fabián y Fuero, quien había tenido la osadía de apelar a la inmunidad eclesiástica para negarse a cumplir la orden que se le había comunicado, en nombre del rey, de expulsar a los clérigos franceses exiliados refugiados en un convento de monjas: "El rey ha tenido un escrito impreso con el título de Carta Pastoral que ha dirigido V. E. a los fieles de la Ciudad de Valencia y su Arzobispado, y se ha enterado de su contenido poco apto para probar la obediencia a las legítimas potestades, de que V. E. tanto habla en él. Esta conducta de V. E. merece el desprecio de S. M. y me manda decirle que, si no se abstiene de tales excesos, serán castigados sus defectos como merecen, pues basta que sepa V. E. el desagrado de S. M. hacia su persona para que procure no salir al público en cosa alguna”. Con la clarísima amenaza que contienen estas líneas, Godoy recordaba a uno de los purpurados más importantes de España (Valencia era el tercer arzobispado de mayores rentas del
} 
a la Monarquía no constituía el único objetivo de Godoy respecto al papel que el clero debía representar en el entramado institucional de la España de Carlos IV. De acuerdo con este pensamiento, el clero debía centrar su actividad no solo en actividades espirituales, sino que también debía de ser partícipe en las tareas que produjesen un beneficio para la Monarquía y, por consiguiente y de acuerdo con el pensamiento del Despotismo Ilustrado, para el conjunto del pueblo. Como ejemplo de esta nueva labor encomendada al clero, puede señalarse la orden de Godoy para que tanto obispos como párrocos se suscribiesen al Semanario de Agricultura y Artes dirigido a los Párrocos, publicación creada por el propio Godoy en 1796. La obligación no solo se limitaba a suscribirse al semanario, los clérigos, además, debían comentar a los fieles en las homilías dominicales los artículos de mayor interés, en una acción de intermediación cultural y educativa. Napoleón había convertido a los clérigos franceses en auténticos funcionarios del Estado con su correspondiente asignación salarial. Sin embargo, la situación en España era diferente, Napoleón nunca contempló que el clero ejerciera otras funciones que las propias de ese estamento, encomendándole el control de las conciencias en aras de la tranquilidad pública, encargando a los prefectos los asuntos que no fueran morales y espirituales.

\section{El fenómeno del afrancesamiento}

Este artículo analiza el fenómeno del afrancesamiento entendido desde un punto de vista histórico, en el contexto de la guerra de la independencia, aunque la temática forme parte de gran número de estudios de carácter social o cultural. El concepto de afrancesado bien pudiera definirse como el sector de la sociedad española que, a raíz de la invasión francesa de España, se postuló a favor de que la monarquía borbónica dejase paso a otra forma de gobernar en la que los elementos fundamentales del sistema bonapartista del país vecino constituyesen el basamento necesario para modernizar las caducas estructuras de la Corona española. ${ }^{18} \mathrm{Su}$ confianza estaba depositada en el nuevo régimen del rey José I, del que esperaban que adoptase los principios del reformismo ilustrado en el ejercicio del poder. ${ }^{19}$ Los afrancesados españoles defendían la necesidad de reformar las bases económicas, sociales y políticas del país para evitar que la crisis secular española otorgara la oportunidad a los postulados revolucionarios de imponerse al pueblo. ${ }^{20} \mathrm{El}$ movimiento afrancesado se componía de un conglomerado heterogéneo de intereses, desde la propia mejora de la situación personal hasta la creencia en la necesidad de "importar» las reformas que había convertido a la Francia de Napoleón en la nación más poderosa de Europa. Los afrancesados españoles se vieron atrapados entre la ilusión de lograr el gobierno reformista de José I y la realidad del ejercicio del poder asumido por los generales del ejército francés. ${ }^{21}$ El Estado afrancesado josefino se presentaba como una entelequia en construcción, cuyo centro neurálgico se situaba en Madrid, debido a la falta de control sobre la casi totalidad del país, en manos de las tropas francesas. ${ }^{22}$

Mucho se ha discutido sobre las verdaderas inclinaciones políticas de los afrancesados, aunque sea incuestionable que, en la nueva monarquía josefina, la negación

reino) que, pese a su dignidad arzobispal, no era más que un súbdito del rey. Y lo que era válido para un arzobispo, valía obviamente para todo el clero. RODRÍGUEZ BREA-LÓPEZ, 1996, pp. 7-34.

${ }^{18}$ MORÁN ORTÍ, 2003, pp. 13-14.

${ }^{19}$ MÉNDEZ BEJERANO, 1912, p. 185.

${ }^{20}$ DUFOUR, 2007, pp. 269-277.

${ }^{21}$ ARTOLA GALLEGO, 2008, pp. 25-27.

${ }^{22}$ LÓPEZ TABAR, 2010, pp. 147-188. 
de jurar fidelidad al rey conllevaba la sanción de la pérdida del empleo, posiblemente de sus posesiones y de su hogar, siempre a cambio de una vaga promesa del logro de una nueva vida, hasta entonces llena de penalidades, al amparo de la ciudad de Cádiz y un futuro incierto en un régimen liberal que se solo se vislumbraría en 1812. Aparte de la influencia ideológica, basada en el erasmismo francés, el afrancesamiento político trajo consigo el colaboracionismo con las tropas francesas. No fueron pocos los miembros del clero español que colaboraron con el invasor francés representado en la figura del rey José I, y que por ello recibieron el calificativo despectivo de afrancesados. ${ }^{23}$

\section{El clero afrancesado}

La Asamblea Nacional francesa había decidido que los sacerdotes que se negaran a prestar el "juramento cívico" serían encarcelados y tendrían la consideración de enemigos del pueblo. ${ }^{24}$ Algunos sacerdotes españoles que habían emigrado al país vecino antes de la Revolución francesa, por su negativa a prestar el juramento, habían regresado a España cruzando la frontera por Hendaya, otros desembarcaron en Bilbao y la Coruña y se asentaron en varias ciudades del reino, como Lérida, Sevilla o Zamora. ${ }^{25}$ A fin de evitar que el clero procedente de Francia influyera en la población, la Real Cédula de 2 de noviembre de 1792 les prohibió celebrar toda clase de actividades religiosas junto con los españoles nacionales. No puede cuestionarse que gran parte del clero apostó por la monarquía josefina. Los cabildos, de hecho, proporcionaron un enorme apoyo a los eclesiásticos afrancesados. José Bonaparte, como embajador en Roma ante la Santa Sede, conocía de primera mano el momento que atravesaba la Iglesia y la necesidad urgente de su reforma. Intervino en el Concordato de 1801, firmado en su propia casa, y a él se debe que Napoleón reconociera el catolicismo como la religión mayoritaria en Francia. ${ }^{26}$

Para el hermano del emperador, la reforma fortalecería su propio poder personal por lo que se procuró que las autoridades eclesiásticas prestasen fidelidad al "rey católico" en el acto juramental, lo que implicaba un apoyo tácito a la causa bonapartista. Además, existían otras razones para el colaboracionismo que iban desde la ideología, hasta el interés egoísta de hacer carrera al lado del poder político, pasando por la aspiración legítima de buscar la paz y modernizar al país y al estamento clerical. ${ }^{27} \mathrm{El} 30$ de mayo de 1808, probablemente inspirado por su amigo Amorós, Llorente envió a las autoridades francesas un Reglamento para la Iglesia española que fue presentado al propio emperador como un plan de reformas fundamentales de la Iglesia. El exordio del Reglamento para la Iglesia española comenzaba así: "Para que haya buen orden en una monarquía es preciso que la división eclesiástica de arzobispados y obispados sea conforme a la civil de provincias y departamentos."28

La respuesta de la Iglesia española ante la invasión francesa no fue monolítica y puede rastrearse en las diferentes posturas adoptadas por los obispos, el clero secular y el clero regular. Ni siquiera en cada uno de estos ámbitos existía unanimidad a la hora de asumir las nuevas ideas para lograr imponerse desde la Administración hasta el resto de los españoles. La mayor parte del clero mostró su negativa huyendo a las zonas no

\footnotetext{
23 Estos habían recibido otros calificativos según avanzaba la ocupación francesa de la península, llamándoseles traidores o juramentados.

${ }^{24}$ SALAS AUSÉNS, 2009, p. 35.

${ }^{25}$ SIERRA NAVA, 1968, pp. 393-396.

${ }^{26}$ MORENO ALONSO, 2008, p. 130.

${ }^{27}$ PRO RUIZ, 2010, pp. 205-220.

${ }^{28}$ LLORENTE, 1808.
} 
invadidas por los franceses, mientras que otra parte se secularizó rompiendo sus votos religiosos.

Dentro del Episcopado, la actitud mayoritaria fue contraria a la colaboración animando a la población a combatir al invasor francés. Muchos obispos abandonaron la sede episcopal de su Obispado ante la cercanía de las tropas de Napoleón. ${ }^{29}$ Sin embargo, no todos se mostraban tan beligerantes con José I y sus ministros. El obispo de Palencia, por ejemplo, acogió favorablemente a las tropas francesas y el obispo de Zamora predicaba la sumisión y fraternidad con el invasor francés. Un tercer grupo de obispos fueron fervientes partidarios del rey José I. Tal es el caso de los obispos de Córdoba, Granada y Zaragoza. ${ }^{30}$ El obispo de Zaragoza, Ramón José de Arce, y su obispo auxiliar, el capuchino fray Miguel Suárez de Santander, fueron acusados de colaboración con los franceses e incriminados como afrancesados.

En el seno del clero capitular podían diferenciarse dos grupos, aquellos que se limitaron a apoyar al invasor francés, y otro grupo que colaboró de forma activa con el gobierno josefino. El primer grupo colaboraba con las autoridades, más por el interés de no perder sus prebendas que por convicción propia, prestaban juramento al rey José I y procuraban que los curas predicasen el mantenimiento de la paz del pueblo con respecto a las tropas invasoras. El segundo grupo estaba formado por aquellos eclesiásticos que, de manera explícita, mostraron su conformidad con el nuevo régimen político y la figura de José I, como era el caso de Félix José Reinoso, que dejaba clara su postura sobre la obediencia debida a las nuevas autoridades francesas en sus escritos:

“(...) los ejemplos, la doctrina del Salvador, las cartas de sus apóstoles dictan la sumisión a las autoridades establecidas, prescindiendo de los principios de su establecimiento. La religión en este caso no autoriza la tiranía, ni sanciona la usurpación: ella no decide las luchas políticas de las naciones, sino mantiene el orden social, asegura la tranquilidad de los habitantes, necesaria para la conservación de la justicia pública."31

Convencidos de la necesaria reforma de la Iglesia, aprobaban la abolición de la Inquisición y de la mayor parte de las órdenes religiosas existentes. ${ }^{32}$ La Pastoral de Félix Amat, dictada desde la abadía de la Granja, el 3 de julio de 1808, constituía un ejemplo claro de la obediencia debida a la Providencia en reconocimiento a la nueva dinastía. "Dios (...) es el que transfiere las coronas y da constitución o fundamento firme a los reinos." "33 Amat era uno de los representantes de la teología afrancesada de la accidentalidad por la que se consideraba que la sustitución de la dinastía de los Borbones por la de Bonaparte, constituía una sucesión legítima en las formas de gobierno. ${ }^{34}$ En este grupo destacaban nombres como los de Juan Antonio Llorente, a quien José I concedió la cantidad de 65000 reales por escribir Disertación sobre el poder que los Reyes españoles ejercieron hasta el siglo duodécimo en la división de obispado, Manuel Vicente Ibarrola, Mazarredo, Manuel Romero y Francisco Terán. ${ }^{35}$ Cuando el invasor francés fue expulsado de España y finalizó la guerra, el clero capitular del primer grupo

\footnotetext{
${ }^{29}$ El obispo de Orense abandonó su sede ante la cercanía de las tropas francesas y rechazó la invitación del mariscal Soult de regresar una vez tomada la ciudad. El arzobispo de Tarragona y los obispos de Lérida, Barcelona, Tortosa, Teruel o Cartagena hicieron lo propio y se refugiaron en Mallorca.

${ }^{30}$ El obispo de Córdoba justificaba su apoyo al rey francés en base a la teoría providencialista de Bossuet, para el que Dios era quien creaba y destruía los reinos, otorgándoselos a quien quisiera por el tiempo de la providencia estimase. DUFOUR, 1987, pp. 158-161.

${ }^{31}$ REINOSO, 1816, p. 88.

${ }^{32}$ MORANGE, 2005, pp. 27-54.

${ }^{33}$ AMAT, 1808.

34 TORRES AMAT, 1835, p. 173.

${ }^{35}$ Juan Antonio Llorente afirmaba que todas las Luces de España estaban reunidas en Madrid y en Cádiz, y que no había diferencias entre los liberales y los afrancesados.
} 
fue tratado con mayor benevolencia por las autoridades fernandinas al considerar que la situación de invasión había obligado a estos eclesiásticos a colaborar para evitar males mayores, pero nunca de manera voluntaria. No fue esta la misma consideración que se mantuvo con los clérigos tildados de afrancesados, pertenecientes al segundo grupo, que fueron vistos como traidores a la patria por haber asumido sin coacción las directrices del poder francés sin contemplar otro interés que el suyo propio. ${ }^{36}$ Muchos de ellos se hicieron francmasones y así, en Madrid, se conocían las logias de los Filadelfos, Edad de Oro, Santa Julia, San Juan de Escocia de la estrella de Napoleón y Beneficencia de Josefina.

El clero secular estaba formado por los clérigos ordenados in sacris. Aparte de los obispos y del alto clero pertenecientes al cabildo, estaba constituido, en su mayor parte, por curas párrocos, tenientes de cura, beneficiados y capellanes, y parte del bajo clero. En términos generales, se trataba de una población caracterizada por su pobreza y su gran movilidad. Al clero parroquial se unían una serie importante de trabajadores vinculados a la Iglesia como sacristanes, campaneros u organistas. La situación del clero parroquial respecto del apoyo al gobierno de José I fue muy diferente a la del clero capitular. La mayor parte de sus miembros aceptaron la presencia del invasor francés sin ningún apoyo, muchos de ellos fueron colaboradores e incluso protagonistas activos de las actividades insurgentes de la guerrilla. No obstante, y especialmente en Andalucía, también se dieron casos de estrecha colaboración con las autoridades josefinas, dirigiendo sus esfuerzos principalmente a predicar entre sus feligreses las bondades del nuevo gobierno, en el convencimiento de que los franceses traerían a España las ideas modernizadoras de la Francia postrevolucionaria.

El clero regular, formado por los monjes y religiosas, representaba más de la mitad de la población eclesiástica del reino. Casi en su totalidad, se declararon patriotas y contrarios a los ocupantes. La desconfianza que esta falta de apoyo generó en el nuevo régimen monárquico fue el motivo que impulsó a José I a suprimir las órdenes religiosas y a obligar a los frailes a su secularización. La sospecha del rey llevó a las autoridades a los registros de conventos sin solicitar el preceptivo permiso eclesiástico. En virtud de los denominados decretos de Chamartín, se consiguió reducir los conventos en una tercera parte, prohibiéndose la nueva admisión de novicios y facilitando la secularización voluntaria. Los bienes provenientes de este sector del clero fueron destinados a financiar la guerra. ${ }^{37}$ En mayo de 1809 se habían publicado varios decretos sancionando las actitudes del clero contrarias al nuevo monarca.

En ese mismo año, en el mes de agosto, se publicó un nuevo decreto por el que se suprimían “(...) todas las órdenes Regulares, Monacales, Mendicantes y Clericales existentes en los dominios de España."38 En 1810, muchos conventos se hallaban desiertos expoliados de toda riqueza aunque, a finales de este mismo año, algunos regulares huidos regresaron manteniéndose gracias a una pensión mensual. En cuanto a los frailes prisioneros, fueron enviados a Francia despojados de sus hábitos y confundidos con el resto de los prisioneros. Los escolapios gozaron de mejor trato, ya que buena parte de ellos trabajaron como maestros en los colegios nuevos de primaria. ${ }^{39}$ Las medidas limitadoras de la actividad religiosa se completaron con un nuevo decreto real que prohibía a los exclaustrados predicar y confesar hasta que se apreciara un cambio de

\footnotetext{
${ }^{36}$ El 2 de mayo de 1809, la Junta Central estableció una lista con los nombres de los acusados de alta traición. Fue publicada en La Gaceta de Madrid de 26 de mayo de 1809, y en ella aparecían los nombres de varios eclesiásticos que por diferentes razones habían colaborado con el régimen de José I.

${ }^{37}$ Prontuario de las leyes y decretos, 1810.

${ }^{38}$ Gaceta de Madrid, 21 de agosto, 1809.

${ }^{39}$ MORENO ALONSO, op. cit., p. 266.
} 
actitud ante el nuevo régimen, así como “(...) formar cuerpos o sociedades para ningún acto religioso ni civil." 40 Los conventos femeninos fueron tratados con mayor benevolencia y no fueron suprimidos por decreto general, aunque se llevó a cabo un agrupamiento de algunas casas monásticas y se dispuso que las religiosas quedaran a las órdenes del obispo respectivo. Tanto en el clero capitular como en el clero parroquial fueron pocos los eclesiásticos a los que se puede definir como afrancesados, si entendemos por este término a aquellos que colaboraron con los franceses por propio convencimiento ideológico. En el apoyo al nuevo monarca pesaron más las motivaciones personales, el anhelo de paz, el deseo de beneficios personales o el objetivo de evitar más destrucción y muertes, que un interés real en que los franceses consolidaran su poder en España. A pesar de que la respuesta a la invasión francesa fue diversa entre el clero español y fue mediatizada por variables diferentes, parece incuestionable que la posición de neutralidad constituía una actitud que no pudieron permitirse ni los eclesiásticos del clero capitular, ni los modestos curas párrocos. Hubieron de tomar partido en favor o en contra de la presencia francesa y eso determinó su futuro una vez finalizada la invasión y la guerra. ${ }^{41}$

Las Cortes de Cádiz acordaron en 1812 suspender todos los nombramientos de eclesiásticos realizados por el gobierno de José I y los generales franceses. ${ }^{42}$ No fueron pocos los cargos capitulares que abandonaron España junto a las tropas francesas en retirada. Tras la batalla de Vitoria, los colaboracionistas se vieron obligados al exilio. Luis XVIII concedió una ayuda como medio de subsistencia a los refugiados españoles concediéndoles una escasa pensión, en relación a la que recibían los mismos cargos en Francia. Entre los religiosos que permanecieron en España, muchos fueron desposeídos de sus cargos y hasta encarcelados por su colaboracionismo con el invasor. Por el contrario, aquellos que se habían negado a aceptar las imposiciones de los franceses fueron proclamados por el nuevo régimen liberal de 1812 como héroes de la patria y merecedores del reconocimiento del pueblo, especialmente los miembros del clero parroquial que habían formado parte de las cuadrillas de la guerrilla que combatió sin descanso al invasor. ${ }^{43}$

El clero español afrancesado había depositado sus esperanzas en el rey José I, confiando en que este, como ocurriera en Nápoles, llevara a cabo un programa de reformas que permitiese sacar a España del atraso secular. La mejor prueba de este anhelo, justificado o no, eran las palabras de Juan Antonio Llorente que, en representación del Cabildo de la Iglesia Metropolitana de Toledo, dirigía al rey:

“(...) que V. M. hizo a Nápoles feliz en menos de dos años, hasta el extremo de olvidar los desastres de una guerra. Espera ver a la España en igual caso dentro de un término más breve con el sabio y paternal gobierno de V. M." 44

En materia religiosa, la labor reformadora del gobierno de José I fue sin duda amplia y de gran calado. ${ }^{45}$ Los eclesiásticos afrancesados fueron partidarios de las

\footnotetext{
${ }^{40}$ Prontuario, I, pp. 313-314.

${ }^{41}$ LÓPEZ TABAR, 2001, p. 77.

42 BARBASTRO GIL, 1993.

${ }^{43}$ Casos como el del Cura Merino son bien conocidos, o el de Francisco Rovira, beneficiado de Bañolas. Rovira combatió a los franceses y, una vez terminada la guerra, fue premiado por sus acciones con la concesión del cargo de arcediano de Valencia.

${ }^{44}$ Gaceta de Madrid de 21 de febrero de 1809.

${ }^{45}$ Fijación de la congrua en un mínimo de 400 ducados anuales el 6 de julio de 1809, supresión, por decreto del 18 de agosto de 1809, de todas las órdenes religiosas, supresión del Voto de Santiago, reorganización de la enseñanza como consecuencia de la desaparición de las escuelas Pías, abolición de toda jurisdicción forense para el clero, atribución de las dispensas matrimoniales a los obispos. Sin olvidar que Napoleón, mediante los decretos de Chamartín, había promulgado la abolición del Santo Oficio.
} 
reformas josefinas pero, a diferencia de los liberales de Cádiz, en su programa de reformas no se incluían aspectos tan fundamentales como la supresión de los privilegios del clero y la nobleza, pilar fundamental del basamento de desigualdad en el que se sustentaba el edificio sociopolítico del Antiguo Régimen. ${ }^{46}$

\section{La necesaria reforma de la Iglesia}

El cambio de dinastía había despejado el camino para la regeneración necesaria del clero. Muchos de sus miembros consideraron el afrancesamiento como una vía de compensación por la desconsideración sufrida en su carrera eclesiástica. El clero afrancesado era consciente de la necesidad de reformar una institución como la Iglesia a la que consideraban corrupta y atrasada, instalada en el tradicionalismo reaccionario ultramontano. Los clérigos afrancesados aborrecían todo aquello que caracterizaba a la religiosidad tradicional en España, la superstición, la piedad popular, la escolástica, etc. Defendían una vuelta a la pureza al primer cristianismo, a la organización primigenia, y algo que les caracterizaba por encima de cualquier diferencia teológica con la jerarquía, la absoluta sumisión de la Iglesia al Estado. Tampoco este hecho era algo ajeno y extraño en el estamento clerical, pues entroncaba con la tradición jansenista de sumisión del poder espiritual al poder temporal del siglo XVIII. El plan de reforma afectaba de modo general al clero y consistía fundamentalmente en la reducción del número de eclesiásticos, la abolición del diezmo y la desamortización del clero suprimido. Además, se limitaba el número de fiestas, se creaba un nuevo sistema de financiación, una nueva organización territorial de la diócesis y parroquias y una nueva escuela de predicación. Por último, se contemplaba la necesidad de firmar un nuevo Concordato con la Santa Sede. ${ }^{47}$ Juan Antonio de Llorente, Francisco Cabarrús, Mariano Luis de Urquijo y Miguel José de Azanza, titular del Ministerio de Negocios Eclesiásticos formularon sus propuestas. Además de contar con la opinión influyente de los clérigos Pedro Estala, Félix Amat, fray Miguel de Santander y Ramón José de Arce.

\section{La Iglesia y la Guerra de la Independencia}

El día 15 de junio de 1808 comenzaron las sesiones de la Asamblea de notables españoles en Bayona. ${ }^{48}$ En las sesiones de la Asamblea, se abordaron los principales asuntos del país y, entre ellos, el religioso fue tratado con prioridad. Napoleón fue consciente de la necesidad de contar con el apoyo de la Iglesia española para "legitimar la ocupación francesa»y, por ello, en la Carta otorgada que aprobó la Asamblea en Bayona, el artículo primero proclamaba que: "la religión católica, apostólica, romana en España y en todas las posesiones españolas, será la religión del Rey y de la Nación y no se permitirá ninguna otra." ${ }^{49}$ Esta actitud conciliadora del emperador hacia la Iglesia

\footnotetext{
${ }^{46}$ Como buenos ilustrados, los afrancesados no dieron el paso definitivo hacía un nuevo sistema político, en el que el concepto de ciudadano sustituyese al de vasallo, esa labor habría de corresponderle al liberalismo español.

${ }^{47}$ MORENO ALONSO, op. cit., p. 29

${ }^{48}$ De los cincuenta clérigos, solo se presentaron en Bayona dieciséis, el resto excusó su ausencia con argumentos como la enfermedad o la inseguridad de los caminos, excepción hecha del ya comentado caso del obispo de Orense.

49 Napoleón era partidario de tolerar otros cultos junto con el reconocimiento de la confesionalidad del Estado, como había demostrado en el Reino de Nápoles, donde se había aprobado una Constitución que admitía, a un tiempo, la confesionalidad del Estado y la tolerancia hacia otros cultos. En el caso de España, el emperador, aconsejado por los delegados españoles reunidos en Bayona, optó por otorgar la exclusividad en materia religiosa a la fe católica, apostólica y romana de España.
} 
española cambió radicalmente después de la derrota francesa en Bailén. De no haberse producido tal derrota, probablemente, un buen número de obispos hubiesen apoyado la Monarquía católica de José I. La victoria española animó a la resistencia al invasor, por lo que fueron creándose Juntas provinciales que reclamaban la presencia de los obispos para formar parte de las mismas y, en algunos casos, incluso presidirlas. ${ }^{50} \mathrm{La}$ intervención personal de Napoleón en la campaña de España tuvo consecuencias dolorosas para el estamento religioso español. El emperador no se olvidó del papel que habían desempeñado muchos curas y monjes españoles en la confrontación con el ejército francés, no solo en el campo de batalla, sino como elementos subversivos y agitadores entre la población española. ${ }^{51}$ En respuesta a esta oposición clerical a la presencia francesa, y también imbuido por sus ideas de progresiva laicidad de la sociedad europea, aprobó varias disposiciones que cuestionaban el tradicional privilegio del que la Iglesia había disfrutado en España. ${ }^{52} \mathrm{Si}$ antes de estas medidas el bajo clero ya había mostrado su animadversión hacia el invasor francés, a partir del 4 de diciembre de 1808, se convirtió en un rival implacable para los intereses del emperador en España. El intento francés de utilizar a la Iglesia española al servicio del emperador fue un fracaso. El clero español no acabó de entender la pretensión de Napoleón de buscar su apoyo para legitimar una Monarquía confesional, a la vez que promulgaba una legislación que expropiaba los bienes eclesiásticos e impedía la actividad del clero regular. El afrancesamiento dentro de la Iglesia española fue un fenómeno casi insignificante dentro del clero rural y menesteroso, y estuvo siempre vinculado al clero urbano, culto y con poder económico y político. ${ }^{53}$

\section{Liberales y afrancesados}

Para los revolucionarios reunidos en Cádiz, el concepto de nación ya no era sinónimo de monarquía. Este grupo de la Cámara gaditana, conocidos como los liberales, situaba al pueblo español como depositario de la soberanía nacional, en una nación formada por ciudadanos iguales ante la ley y sin privilegios, con una concepción laica de la sociedad, en la que la Iglesia ya no disfrutase de la situación de favor que había mantenido a lo largo de la historia de España. Esta idea chocaba frontalmente con los eclesiásticos reformistas, que entendían el concepto de libertad como la oportunidad de reformar la Iglesia. ${ }^{54}$ Sin embargo, los liberales no disponían de la mayoría en las Cortes gaditanas y tuvieron que sacrificar su objetivo de libertad religiosa en aras de la libertad política. ${ }^{55}$ A pesar de esta concesión a la Iglesia, en 1808, el clero español reaccionó a lo que consideraba un ataque del liberalismo a su tradicional estatus de privilegio, lo que

\footnotetext{
${ }^{50}$ En muchas Juntas la presencia eclesiástica era significativa. En la Junta de Granada, por ejemplo, además del arzobispo, se integraron el deán, cuatro canónigos, dos párrocos, dos capellanes reales y varios prelados del clero regular.

${ }^{51}$ FRASER, 2006, pp. 18-19.

${ }^{52}$ El 4 de diciembre de 1808 se dictaban los llamados "decretos de Chamartín". Dos decretos que abolían el Santo Oficio y ordenaban la supresión de la tercera parte de los conventos de los territorios bajo ocupación francesa y la nacionalización de sus bienes. En 1809, el cobro del diezmo pasó a ejecutarse por parte del Estado, se vendieron las propiedades incautadas a los conventos suprimidos y se clausuraron los pocos recintos monásticos que habían permanecido abiertos tras la publicación de los referidos decretos.

${ }^{53}$ Al finalizar la guerra contra el ejército invasor, de un total de 150.000 eclesiásticos, solo 252 sintieron la necesidad de exilarse en el país vecino por su colaboración con los franceses. Estas cifras pueden ofrecer una idea aproximada de la presencia del fenómeno del afrancesamiento en el ámbito religioso español.

${ }^{54}$ MARTÍNEZ QUINTEIRO, 1977, pp. 15-20.

55 El artículo 12 de la Constitución de 1812 decía así: "La religión de la Nación española es y será perpetuamente la católica, apostólica, romana, única verdadera. La Nación la protege por leyes sabias y justas y prohíbe el ejercicio de cualquiera otra."
} 
ocasionó una cierta radicalización de su postura ante el Estado. ${ }^{56}$ Los eclesiásticos afrancesados fueron los más damnificados por esta polarización entre una Iglesia, cada vez más reaccionaria, y un Estado liberal, decidido a acabar con los privilegios del clero español. Así se expresaba Félix José Reinoso al respecto del liberalismo gaditano:

"Los mismos apóstoles de la liberalidad de ideas han querido introducir los grillos de esclavitud hasta en el cerebro de los hombres; y cuando levantaban el grito contra las pesquisas de los errores en materias de religión, establecían una inquisición, la más funesta y arbitraria, contra los errores políticos, contra las equivocaciones, y aún sobre la ignorancia de los hechos." 57

Gran parte del estamento eclesiástico español recibió positivamente la Constitución de $1812 .^{58}$ No en vano, el artículo 12 de la Carta Magna otorgaba a la religión católica una posición de privilegio indiscutible en el ámbito de la profesión de fe en España. ${ }^{59}$ La Constitución de Bayona de 1808 ya recogía, en su artículo 11, el reconocimiento de la religión como vínculo entre la nación y la Corona con el objetivo de acercar al rey francés a un pueblo que le consideraba un usurpador. Esta posición favorable del clero hacia "la Pepa" cambió cuando los liberales abolieron el Tribunal de la Inquisición y comenzó la reforma del clero regular. ${ }^{60}$

\section{Política religiosa}

El régimen Josefino en materia religiosa, tutelado por Napoleón, fue un firme partidario de la reforma del estamento eclesiástico español. ${ }^{61}$ Sus propuestas reformistas intentaron atraer para sí a los sectores más avanzados del clero, a los intelectuales y a los ilustrados más críticos con el gobierno de Carlos IV. La Iglesia hispana se resistió a la política reformista josefina, recelosa de perder sus privilegios y sus riquezas, y convirtieron en un enfrentamiento político con el Estado lo que no era más que un intento de suprimir las prebendas de las que había disfrutado la Iglesia en España durante siglos. ${ }^{62}$ No obstante, tanto el emperador como su hermano eran conscientes del significado de la religión para la sociedad española de la época por lo que estas reformas no eran contrarias al clero y a la Iglesia, sino que pretendían abordar cuestiones propias del estamento clerical. Los decretos de Chamartín fueron mucho más que un intento de beneficiarse de los bienes materiales del Santo Oficio y de las órdenes regulares suprimidas. Napoleón pretendía legitimar en Francia su política expansiva en Europa, que conllevaba el reclutamiento de los jóvenes franceses y fue vista con recelo por la población. Solo la misión civilizadora del Ejército napoleónico, y en ella estaba incluida la lucha contra el sentimiento supersticioso y oscurantista del pueblo español, fruto del poder de la Iglesia, justificaba el sacrificio de la juventud francesa. ${ }^{63}$ La persona elegida por el emperador para llevar a cabo la reforma de la Iglesia en España fue su capellán mayor, el arzobispo

\footnotetext{
${ }^{56}$ SANCHÍS VIDAL; RAMOS ROVI, 2017, pp. 307-317.

${ }^{57}$ REINOSO, op.cit., p. 242.

${ }^{58}$ LA PARRA LÓPEZ, 1985, pp. 73-93.

59 "La religión de la nación española es y será perpetuamente la católica, apostólica, romana, única verdadera. La nación la protege por leyes sabias y justas, y prohíbe el ejercicio de cualquier otra»

${ }^{60}$ DE VILLAPADIERNA, 1955, 275-335.

${ }^{61}$ Buena prueba de la influencia de Napoleón sobre José I en materia religiosa fue la promulgación de los Decretos Imperiales de 1808, más conocidos con el nombre de Decretos de Chamartín. LA PARRA, op. cit.

${ }^{62}$ El canónigo Juan Antonio Llorente fue el verdadero inspirador del espíritu reformista del Gobierno de José I. DUFOUR, 1982, p. 25.

${ }^{63}$ DUFOUR, 1989, p. 77.
} 
de Malinas Dominique de Pradt. ${ }^{64}$ El clérigo francés defendía una serie de medidas que tenían como objetivo último el sometimiento del poder eclesiástico al poder civil, en definitiva, de la Iglesia al Estado. Su plan se había inspirado en la Constitución civil del clero y en el Concordato de 1801, que pretendía someter la práctica de la religión católica a los reglamentos de policía que el gobierno pudiera dictar. De Pradt resultó ser mucho más radical con este plan que Juan Antonio Llorente con su "Reglamento propuesto para la Iglesia española», ante el emperador francés, y que Miguel José Azanza de Alegría, ministro de Negocios Eclesiásticos, con su Plan General del clero. El hecho de que un eclesiástico francés fuera el encargado de reformar la Iglesia española de acuerdo con los dictados de Napoleón pone en cuestión la verdadera influencia atribuida al clero afrancesado en el cambio experimentado por el estamento religioso. ${ }^{65}$

A pesar de la influencia de Napoleón sobre su hermano José I, también en materia religiosa, este tuvo la habilidad de atraerse al sector del clero español defensor de la necesidad de reforma de la Iglesia española. Este sector fue tildado de afrancesado por los eclesiásticos refractarios a cualquier cambio que cuestionara sus tradicionales privilegios. La Iglesia aportó personalidades de la máxima autoridad a la causa francesa, entre ellos, Juan Antonio Llorente fue el más claro exponente del clero español. Llorente estaba dispuesto a colaborar con los franceses si con ello se conseguía la ansiada reforma de la Iglesia en España. Los hechos acaecidos en mayo de 1808 le ofrecieron la oportunidad de llevar a cabo los principios reformistas que ya había manifestado con motivo del llamado cisma de Urquijo en $1799 .{ }^{66}$ El 30 de mayo de 1808 , Llorente envió a las autoridades francesas su plan para reformar la Iglesia española bajo el título Reglamento para la Iglesia española. Este documento llegó incluso al propio emperador. ${ }^{67}$ La propuesta del religioso español sintonizaba a la perfección con el sistema organizativo de la Iglesia francesa impuesto por Napoleón. Básicamente, el modelo de Llorente proponía que la organización eclesiástica coincidiese con la civil y militar y, lo que era más importante, aspiraba a que la Iglesia dejase de ser nacional para pasar a ser estatal. Su intención era que el poder eclesiástico fuera sometido al poder político. Lo que pudiera parecer una novedad en la secular relación entre Iglesia y Estado, no era más que la plasmación del más rancio regalismo hispano que, desde la época de los Reyes Católicos, había enrarecido la relación entre la Corona española y Roma. De acuerdo con este pensamiento, el clero debía obediencia al Estado, fuera quien fuese el monarca, e incluso el régimen político. Esta circunstancia reviste especial importancia para lograr entender la relación del llamado clero afrancesado con el invasor, puesto que la colaboración no se entendía como la sumisión del estamento clerical a José I, sino como la primacía del poder político sobre una organización, la Iglesia, como parte del propio Estado. ${ }^{68}$ Desde estas premisas ideológicas, el religioso afrancesado negaba la propia organización institucional de la Iglesia, que debía constituir la reunión de los fieles y abandonar su estructura jerarquizada. Esta concepción del estamento clerical no solo le

\footnotetext{
${ }^{64}$ El minucioso estudio del estamento eclesiástico español por Dominique de Pradt concluía que el clero, especialmente el regular, era causa del atraso español, y lo que era más significativo para los intereses franceses, las órdenes regulares ejercían de catalizador del descontento popular y de oposición política a la presencia francesa en España. MORENO ALONSO, op. cit., pp. 297-303 y 361-362.

${ }^{65}$ BARBASTRO GIL, op.cit., 2008, pp. 267-295.

66 Tras la muerte del Papa Pío VI, el secretario de Estado de Carlos IV, Mariano Luis de Urquijo, hizo firmar al rey, el 5 de septiembre de 1799, un Real Decreto por el que los obispos españoles pasaban a depender exclusivamente de la Corona.

${ }^{67}$ DUFOUR, 2014, pp. 23-49.

${ }^{68}$ Llorente llegaba incluso a denunciar la existencia de la figura del Concordato por entender que no podía establecerse una relación jurídica entre iguales por parte del Estado y la Iglesia, convencido de la primacía del poder político sobre cualquier otro en el marco del Estado.
} 
alejaba de la tradicional postura de la Iglesia en España, sino que, a ojos de la jerarquía católica, le acercaba peligrosamente al protestantismo. Llorente defendía la necesidad de que la Iglesia estuviese al servicio del Estado, no de la nación, toda una novedad en la historia de España, condenada tanto por el poder político como por el religioso. ${ }^{69} \mathrm{La}$ reforma que quería introducir José I, inspirada en los postulados de los ilustrados españoles, pretendía mantener la estructura básica del estamento religioso español. Aunque esta reforma fue más lejos en su afán reformista que la propia Constitución de 1812, nunca puso en cuestión el papel de la Iglesia como actor fundamental en el escenario sociopolítico español de comienzos del siglo XIX. ${ }^{70}$

\section{Los afrancesados y el Estado}

El pensamiento afrancesado había surgido entre la élite cultural española que concebía a Francia como el mejor ejemplo de lo que significaba la civilización histórica europea, una visión cosmopolita y racionalista que entraba en conflicto con el tradicionalismo católico español. Los afrancesados fueron rechazados tanto por los monárquicos absolutistas como por los liberales gaditanos, que anteponían la idea de nación a la idea afrancesada de Estado. Para lograr construir un Estado moderno al estilo europeo, los llamados afrancesados se pusieron al servicio de José I en el convencimiento de que las ideas modernizadoras que habían transformado Francia en la vanguardia cultural, política y económica de Europa producirían el mismo efecto en su país, que arrastraba, desde el siglo XVII, un secular atraso. Esta concepción ideológica, pese al nombre, había surgido antes de 1808, remontándose a la segunda mitad del siglo XVIII, con un claro matiz de reformismo ilustrado y, que al igual que en el reinado de José I, perseguía como fin último la modernización del país bajo un régimen político autoritario.

El propio concepto de Estado en su acepción contemporánea, como una forma de organización política diferenciada del monarca y la Corona, es utilizado por primera vez en España por los afrancesados, aunque fue la historiografía liberal quien se adjudicó la primacía semántica del término Estado. Los afrancesados entendían el Estado como la materialización de las ideas ilustradas de Administración, Gobierno, uniformidad, utilidad, modernidad, etc., siempre con el monarca que habría de modernizar España a la cabeza del aparato institucional. La Iglesia, como institución, acaparaba gran poder por lo que, para los afrancesados, suponía un serio obstáculo a la hora de materializar su idea de Estado. En el Estatuto de Bayona se incluía, por primera vez, el topónimo España como definición oficial del Estado. Los afrancesados rompían con la tradicional concepción de España como un conglomerado de reinos, como un ente en el que la Corona fuese la institución vinculante de los diversos territorios que formaban el país. El Estatuto estableció la unidad de fuero del país, eliminando toda clase de privilegios estamentales, jurisdicciones especiales y fueros territoriales. ${ }^{71}$ Los afrancesados se consideraban patriotas que deseaban modernizar a su país y colocarlo a nivel internacional como una más de las potencias europeas. Este sentido patriótico, sin embargo, distaba mucho del pensamiento de sus rivales políticos, tanto absolutistas como liberales, que les tildaban de traidores. ${ }^{72}$ Esta acusación procedía de la consideración de que habían entregado el trono español al emperador francés, eludiendo tanto la voluntad

\footnotetext{
${ }^{69}$ BARRERO ORTEGA, 2005, p. 14.

${ }^{70}$ DUFOUR, 2007, p. 276.

${ }^{71}$ Arts. 96 y 98.

${ }^{72}$ Los afrancesados consideraban que los liberales defendían los intereses británicos contra el emperador y, por tanto, también se les podía considerar traidores a la patria. La derrota de Napoleón supondría para España perder la oportunidad de homologarse con los países más modernos y prósperos de Europa.
} 
como la tradición nacional. No era de la misma opinión Juan Antonio Llorente, uno de los más fervientes defensores de la necesidad de reformar la Iglesia española con la ayuda del poder político representado por José I:

“(...) Esta no se ha de calcular por el modo de pensar de unas pocas personas cuyo interés ha sido, es y sería siempre contrario al bien común de la nación, como tienen reconocido y publicado justamente los vocales de las citadas Cortes. La opinión nacional se debe investigar por medio de los votos que pronuncien los interesados en la práctica de una constitución liberal como la de Bayona, sea con las ampliaciones que le ha dado la de la Isla de León, sea con la mejora que le proporcione la nación entera congregada legítimamente por su rey José I."73

\section{Conclusiones}

La influencia ideológica del país vecino en la España de principios del siglo XIX marcó un antes y un después en la historia de nuestro país ya que supuso un enfrentamiento bélico de gran trascendencia para dos bandos de la población española. Los historiadores han debatido sobre si el afrancesamiento fue el causante de una revolucionaria lucha por la religión. Sin embargo, no parece que la intención de los afrancesados tuviera como destino final llevar a cabo un ataque directo a la religión, aunque sí parece cierto que supo utilizarse como herramienta política para apoyar el asentamiento de un nuevo régimen político en España. La reforma de una fe católica muy arraigada en el país, pudo utilizarse como excusa por los bonapartistas con el argumento de que la reforma religiosa propuesta podría dotar de nueva savia a las creencias de la mayoría de los españoles. Sin embargo, la opinión pública no estaba preparada para reformar la Iglesia al gusto francés y, en el plano político, tampoco aceptarían de buen grado el cambio de dinastía. Sin duda, los cambios ofertaban nuevos puntos de vista a las instituciones con mayor arraigo en España: la corona y la Iglesia católica.

En este artículo se ha puesto de manifiesto que el clero se dividió y enfrentó en base a la causa del emperador francés. Aunque no todo el clero tomó partido en la contienda, la conducta bifronte del clero afrancesado puede explicarse desde diversos puntos de vista. En el orden político, consideraban que de Francia procederían las reformas que el país necesitaba, evitando veleidades revolucionarias que pudiesen acabar con el sistema político en el que se sustentaba el Antiguo Régimen. Por otra parte, los clérigos afrancesados defendían un marco político basado en cartas otorgadas y no en constituciones, a la manera liberal, porque temían más a la soberanía nacional, poder constituyente, que a los invasores franceses. Desde un punto de vista ideológico, los franceses se situaban más cerca del liberalismo doctrinario, que este último de los liberales progresistas. El eclesiástico afrancesado Félix José Reinoso personifica, como claro exponente, este corpus ideológico, defendiendo en su obra Examen de los delitos de infidelidad a la patria imputados a los españoles bajo la dominación francesa que la soberanía debía residir en la Corona y no en el pueblo, y que el poder de la aristocracia y del clero debían continuar soportando, como pilares fundamentales, el gobierno de la nación. Juan Antonio Llorente, insigne representante del clero afrancesado, justificaba la obediencia a las autoridades francesas incluso justificándolo en la tradición clásica. Liberales y afrancesados eran hijos ideológicos de Francia, pero mientras los primeros defendían la soberanía nacional, los afrancesados se posicionaban del lado del monarca, al sentir verdadero temor a que el poder político se desplazara al pueblo.

Para expertos, como Moreno Alonso, el clero afrancesado nunca se sintió influido por La Enciclopedia sino por la estabilidad y la prosperidad que el gobierno de José

\footnotetext{
${ }^{73}$ LLORENTE, 1813, p. 10.
} 
Bonaparte podría garantizarles. ${ }^{74}$ A pesar de esta ventaja, el emperador no supo valorar en su justo término la fuerte religiosidad del pueblo español, anteponiendo a esta unas ideas regeneradoras que la opinión pública rechazó con sus propias armas. En consecuencia, puede afirmarse que la cuestión religiosa se configuró como un factor determinante y clave para la comprensión histórica de la reacción del pueblo español contra el invasor francés.

\section{REFERENCIAS BIBLIOGRÁFICAS}

ARTOLA GALLEGO, Miguel, Los afrancesados, Madrid, Alianza Editorial, 2008.

BARBASTRO GIL, Luis, Los afrancesados. Primera emigración política del siglo XIX español (1813-1820), Alicante, Instituto de Cultura Juan Gil-Albert, 1993.

BARBASTRO GIL, Luis, "Plan de reforma de la Iglesia española impulsado por Napoleón Bonaparte", Hispania Sacra, 121, 2008, pp. 267-295.

BARRERO ORTEGA, Abraham, Modelos de relación entre el Estado y la Iglesia en la historia constitucional de España, Cádiz, Universidad de Cádiz y Fundación Centro de Estudios Constitucionales 1812, 2005.

DÍAZ DE CERIO RUIZ, Franco, Noticias sobre España en el fondo "Secretaría de Estado: SS, (249)" del Archivo Vaticano (1800-1817), Roma, Publicaciones Instituto Español de Historia Eclesiástica, 1988.

DE VILLAPADIERNA, Isidoro, "El episcopado español y las Cortes de Cádiz”, Hispania Sacra, VIII, 1955, pp. 275-335.

DUFOUR, Gérard, Juan Antonio Llorente en France (1813-1822). Contribution à l'étude du libéralisme chrétien en France et en Espagne au début du XIXe siècle, Genève, Droz, 1982.

----- La Guerra de la Independencia, Madrid, Historia 16, 1989.

---- "Los afrancesados o una cuestión política: los límites del despotismo ilustrado", Cuadernos de Historia Moderna. Anejos, VI, 2007, pp. 269-277.

----- Gérard, "Juan Antonio Llorente de corifeo del afrancesamiento a mártir del liberalismo", Ayer, 95, 2014, pp. 23-49.

FERNÁNDEZ SARASOLA, Ignacio, La Constitución de Bayona (1808), Madrid, Iustel Publicaciones, 2007.

FRASER, Ronald, La maldita guerra de España: historia social de la Guerra de la Independencia.1808-1814, Barcelona, Crítica, 2006.

GORÁFANO SÁNCHEZ, Rafael, PÁRAMO ARGÜELLES, Juan Ramón de, La Constitución gaditana de 1812, Cádiz, Diputación provincial de Cádiz, 1987.

JOVER ZAMORA, José María, Política, diplomacia y humanismo popular. Estudios sobre la vida española en el siglo XIX, Madrid, Turner, 1976.

LA GACETA DE MADRID, 1809.

LA PARRA LÓPEZ, Emilio, El primer liberalismo español y la Iglesia, Alicante, Diputación Provincial, 1985.

LÓPEZ TABAR, Juan, "José I y los afrancesados. Otra España posible", en SALVADOR BENÍTEZ, Antonia, (dir.), De Aranjuez a Cádiz: por la libertad y la Constitución, Aranjuez, Marañón-Ayuntamiento de Aranjuez, 2010, pp. 147-188.

LÓPEZ TABAR, Juan, Los famosos traidores. Los afrancesados durante la crisis del Antiguo Régimen (1808-1833), Madrid, Biblioteca Nueva, 2001.

LLORENTE, Juan Antonio, Discurso sobre la opinión nacional de España acerca de la guerra con Francia, Zaragoza, Ofician de Miedes, 1813.

MARTÍNEZ QUINTEIRO, María Esther, Los grupos liberales antes de las Cortes de Cádiz, Madrid, Narcea, 1977.

MÉNDEZ BEJERANO, Mario, "Historia política de los afrancesados", Revista de Archivos, Bibliotecas y Museos, XXV, 1912, pp. 185-186.

\footnotetext{
${ }^{74}$ MORENO ALONSO, op. cit., p. 604.
} 
MORALES MOYA, Antonio, "Los conflictos ideológicos en el siglo XVIII español”, Revista de Estudios Políticos, 80, 1993, pp. 7-37.

MORÁN ORTÍ, Manuel, "La formación de las Cortes (1808-1810)", en Artola Gallego, Miguel, (ed.), Las Cortes de Cádiz, Madrid, Marcial Pons, 2003, pp. 13-36.

MORANGE, Claude, “¿Afrancesados o josefinos?”, Spagna contemporanea, 87, 2005.

MORENO ALONSO, Manuel, José Bonaparte, un rey republicano en el trono de España, Madrid, La Esfera de los Libros, 2008.

---- $\quad$ El clero afrancesado en España. Los obispos, curas y frailes de José Bonaparte, Madrid, Biblioteca Nueva, 2014.

PÉREZ LEDESMA, Manuel; SIERRA, María, (eds.), Culturas políticas: teoría e historia, Zaragoza, Institución Fernando el católico, 2010, pp. 205-231.

PÉREZ SÁENZ DE URTURI, Juan Eusebio, "La libertad religiosa en el Estatuto Constitucional de Bayona (1808)", Anales de Historia Contemporánea, 4, 1985, pp. 55-78.

PRONTUARIO DE LAS LEYES Y DECRETOS, 1810.

PRO RUIZ, Juan, "Afrancesados: sobre la nacionalidad de las culturas políticas", en Pérez Ledesma; Manuel y Sierra Alonso, María (ed.), Culturas políticas: teoría e historia, Zaragoza, Institución Fernando el católico, 2010, pp. 205-231

REINOSO, Félix José, Examen de los delitos de infidelidad a la patria imputados a los españoles bajo la dominación francesa, Auch, Imprenta de la Sra. Viuda de Duprat, 1816.

SALAS AUSÉNS, José Antonio, En busca de El Dorado. Inmigración francesa en la España de la Edad Moderna, Bilbao, Universidad del País Vasco, 2009.

SANCHÍS VIDAL, Amelia; RAMOS ROVI, María José, "Influencia del catolicismo en la Constitución gaditana. Análisis del juramento y la representación eclesiástica por Andalucía", Hispania Sacra, 69, 2017, pp. 307-317.

SANZ CID, Carlos, La Constitución de Bayona, Madrid, Reus, 1922.

SIERRA NAVA, Luis, "La inmigración del clero francés en España", Hispania, 28, 1968, pp. 383-424.

TORRRES AMAT, Félix, Vida del Ilmo. Señor don Félix Amat, arzobispo de Palmyra, Madrid, Imprenta Fuentenebro, 1835.

VELASCO MOLPECERES, Ana María, Moda y prenda femenina en España (siglo XIX), Madrid, Ediciones XIX, 2016. 